\title{
ESTAGIÁRIOS DE PEDAGOGIANA GESTÃO UNIVERSITÁRIA: DO ACOMPANHAMENTO À RELAÇÃO TEORIA E PRÁTICA
}

\author{
Alan Leite Moreira ${ }^{1}$ \\ Ana Paula Furtado Soares Pontes ${ }^{2}$
}

RESUMO: Esta pesquisa teve por objetivo caracterizar e discutir o acompanhamento do estágio não obrigatório de estudantes de Pedagogia que atuavam em setores/projetos não diretamente relacionados ao ensino em uma Universidade Federal brasileira, bem como analisar a relação teoria-prática presente nessa experiência formativa. Para isso, foi realizada uma entrevista semiestruturada com a Coordenadora de Estágio da Instituição, com os supervisores/orientadores de estágio e com os estagiários. O tratamento desses dados se deu por meio da análise de conteúdo. Evidenciou-se o distanciamento entre a Coordenação de Estágio, os supervisores/orientador-estagiários e o curso de Pedagogia, bem como a frágil relação teoria-prática.

Palavras-chave: Estágio. Pedagogia. Universidade.

PEDAGOGY INTERNS ON UNIVERSITY MANAGEMENT FROM THE FOLLOW-UP TO THE RELATIONSHIP BETWEEN THEORY AND PRACTICE

ABSTRACT: This study aims to characterize and discuss the follow-up of non-mandatory internship for pedagogy students who worked in departments/projects not directly related to education at a Brazilian Federal University as well as to analyze the relationship between theory and practice in this training experience. Thus, it used a semistructured interview with the Internship Coordinator of this educational institution, the internship supervisors/advisors, and the interns. Data processing was done through Content Analysis. It has shown the detachment among the Coordination of the internship, the internship supervisors/advisors - interns, and pedagogy major as well as the fragile relationship between theory and practice.

Keywords: Internship. Pedagogy. University

\footnotetext{
${ }^{1}$ Professor Ms. da Rede Estadual de Ensino da Paraíba. E-mail alanpb@hotmail.com

2 Profa. Dra. da Universidade Federal da Paraíba - UFPB.
} 


\section{ESTAGIARIOS DE PEDAGOGÍA EN LA GESTIÓN UNIVERSITARIA: DEL ACOMPAÑAMIENTO A LA RELACIÓN TEORÍA-PRÁCTICA}

RESUMEN: Esta investigación tuvo por objetivo caracterizar y discutir el seguimiento de la práctica no obligatoria de estudiantes de Pedagogía que actuaban en sectores / proyectos no directamente relacionados a la enseñanza en una Universidad Federal brasileña, así como analizar la relación teoría-práctica presente en esa experiencia formativa. Para ello, se realizó una entrevista semiestructurada con la Coordinadora de Etapa de la Institución, con los supervisores / orientadores de prácticas y con los pasantes. El tratamiento de los datos se dió a través del análisis de contenido. Se evidenció el distanciamiento entre la Coordinación de Prácticas, los supervisores / orientadorpasantes y el curso de Pedagogía, así como la frágil relación teoría-práctica.

Palabras clave: Práctica. Pedagogía. Universidad.

\section{Introdução}

Estágio, segundo a Lei № 11.788, de 25 de setembro de 2008 (BRASIL, 2008), é compreendido como "ato educativo escolar supervisionado, desenvolvido no ambiente de trabalho, que visa à preparação para o trabalho produtivo de educandos que estejam frequentando o ensino regular [...]" e, como tal, requer "acompanhamento efetivo pelo professor orientador da instituição de ensino e por supervisor da parte concedente". Para que a atividade se configure efetivamente como estágio, essa Lei também prevê a observação de alguns requisitos, tais como: celebração de Termo de Compromisso de Estágio (TCE) e de Plano de Atividades de Estágio (PAE), entre o educando, a parte concedente do estágio e a instituição de ensino; acompanhamento efetivo pelo professor orientador da instituição de ensino e por supervisor da parte concedente; apresentação periódica do educando de relatório das atividades, em prazo não superior a 6 (seis) meses; seguro contra acidentes pessoais em favor do estagiário; dentre outros.

No âmbito das políticas públicas voltadas para a formação de professores, em observância ao que define a Lei de Diretrizes e Bases da Educação Nacional (BRASIL, 1996), as Diretrizes Curriculares Nacionais para o curso de graduação em Pedagogia (DCNP), definidas por meio da Resolução do $\mathrm{CNE}^{3}$ № 1, de 15 de maio de 2006, determinam a integralização de Estágio. Desenvolvido ao longo do curso, ele deve assegurar aos graduandos experiência de exercício profissional em ambientes escolares e

\footnotetext{
${ }^{3}$ Conselho Nacional de Educação.
} 
não-escolares, que ampliem e fortaleçam atitudes éticas, conhecimentos e competências,

\begin{abstract}
a) na Educação Infantil e nos anos iniciais do Ensino Fundamental, prioritariamente; b) nas disciplinas pedagógicas dos cursos de Ensino Médio, na modalidade Normal; c) na Educação Profissional na área de serviços e de apoio escolar; d) na Educação de Jovens e Adultos; e) na participação em atividades da gestão de processos educativos, no planejamento, implementação, coordenação, acompanhamento e avaliação de atividades e projetos educativos; f) em reuniões de formação pedagógica (BRASIL, 2006, grifos nossos).
\end{abstract}

Nesse sentido, o Projeto Pedagógico do Curso (PPC) de graduação em Pedagogia, Licenciatura, do Centro de Educação, Campus I (João Pessoa) da Universidade Federal da Paraíba (UFPB), por meio da Resolução CONSEPE/UFPB № 64, de 25 de outubro de 2006, definiu não apenas a docência como campo de atuação profissional, mas também a gestão educacional e a produção e difusão do conhecimento científico e tecnológico do campo educacional.

Apesar de prever um campo amplo de atuação para além da sala de aula, a composição curricular do curso de Pedagogia reserva, dentre suas 3.210 horas totais, apenas 60 (sessenta) horas de estágio em área diferente a do Magistério. Ao todo, o curso reserva 300 (trezentas) ${ }^{5}$ horas de estágio supervisionado, que são divididas, sequencialmente, a partir do 4으 (diurno) ou 5ㅇ (noturno) período letivo, em cinco estágios de 60 (sessenta) horas: I (Gestão Educacional); II (Magistério da Educação Infantil); III (Magistério do Ensino Fundamental); IV (Magistério do Ensino Fundamental) e V (Área de Aprofundamento).

Quanto às áreas de aprofundamento, o PPC de Pedagogia prevê apenas duas: Magistério de Jovens e Adultos e Magistério da Educação Especial, sendo reservadas, além das 60 (sessenta) horas de "Estágio Supervisionado V", outras 180 (cento e oitenta) horas para três disciplinas nos conteúdos complementares, a serem integralizadas no último período letivo do curso. Dessa forma, conforme aponta Munhós (2007), nos cursos de Pedagogia por ele analisados ${ }^{6}$, são percebidas preocupações em

\footnotetext{
${ }^{4}$ Conselho Superior de Ensino, Pesquisa e Extensão.

${ }^{5}$ As novas Diretrizes Curriculares Nacionais (DCNs) para os cursos de licenciatura apontam a elevação da carga horária de estágio para 400 (quatrocentas) horas (BRASIL, 2015), devendo os cursos de formação de professor se adequar até Julho de 2018 (BRASIL, 2017).

${ }^{6}$ Os cursos de Pedagogia analisados foram os da Universidade do Estado de Minas Gerais (UEMG), Universidade Federal de Minas Gerais (UFMG) e Universidade Presidente Antônio Carlos (UNIPAC).
} 
definir um aprofundamento profissional prioritário na área da docência, secundarizando a formação do gestor dos processos educativos e do pesquisador em educação e ensino, que são também funções indispensáveis à formação do educador e, consequentemente, do Pedagogo.

No contexto institucional da UFPB, o estágio não obrigatório se constitui em atividade complementar à formação acadêmico-profissional, compatível com o horário acadêmico, podendo este ser considerado como um componente curricular obrigatório, optativo ou flexível (UFPB, 2015). No curso de Pedagogia, o aproveitamento dessa experiência para fins de integralização curricular poderá ocorrer mediante aprovação do Colegiado do Curso.

Quanto à realização do Estágio não obrigatório interno, desenvolvido na própria Instituição, a UFPB, como autarquia federal e detentora de autonomia, contrata estudantes para atuarem como estagiários em seus diversos ambientes de trabalho, concedendo compulsoriamente bolsa e auxíliotransporte. Tal contratação, além de atender à Lei № 11.788/2008, à Orientação Normativa MPOG ${ }^{7}$ № 02/2016 e à Resolução CONSEPE/UFPB № 16/2015, também é regulamentada, na UFPB, por meio da Instrução Normativa Conjunta PROGEP/PROPLAN/PRG/GR ${ }^{8}$ № 01/2016, que dispõe sobre os procedimentos relativos à solicitação da contratação de estagiários, modalidade de estágio curricular supervisionado não obrigatório interno (bolsa-estágio), para o âmbito dos setores administrativos e acadêmicos da UFPB.

Diante de uma possível lacuna na formação dos estudantes do curso de Pedagogia, pressupomos que, de alguma forma, esta pode ser suprida por meio do estágio não obrigatório, uma vez que esta atividade curricular, nos cursos de formação de professores, visa à aproximação da realidade e à consequente reflexão teórica e ao aprofundamento em direção à prática-teoria-prática recriada (PICONEZ, 2012), tomando como eixo, desta experiência formativa, a integração da teoriaprática. Portanto, este artigo, que constitui um recorte dos resultados da dissertação desenvolvida no Mestrado Profissional em Políticas Públicas, Gestão e Avaliação da Educação Superior (MPPGAV), vinculado ao Centro de Educação (CE) da UFPB, objetivou caracterizar e discutir o acompanhamento e

\footnotetext{
${ }^{7}$ Ministério do Planejamento, Desenvolvimento e Gestão.

8 Pró-Reitoria de Gestão de Pessoas, Pró-Reitoria de Planejamento e Desenvolvimento, Pró-Reitoria de Graduação e Gabinete da Reitoria.
} 
a relação teoria-prática no estágio não obrigatório dos estudantes de Pedagogia que realizavam atividades em uma área de atuação diferente à da sala de aula na UFPB/Campus I (João Pessoa).

\section{Acompanhamento do estágio}

Quanto ao acompanhamento pedagógico do estágio, uma das obrigações da instituição de ensino é "indicar professor orientador, da área a ser desenvolvida no estágio, como responsável pelo acompanhamento e avaliação das atividades do estagiário" (BRASIL, 2008). Além disso, cabe à parte concedente "indicar funcionário de seu quadro de pessoal, com formação ou experiência profissional na área de conhecimento desenvolvida no curso do estagiário, para orientar e supervisionar estagiários" (BRASIL, 2008).

No âmbito da UFPB, a atividade de estágio é gerenciada pela Coordenação de Estágio e Monitoria da Pró-Reitoria de Graduação (CEM/PRG) e disciplinada por meio da resolução do CONSEPE/UFPB № 16/2015, que aprovou o regulamento dos cursos regulares de graduação da Instituição. Quanto ao acompanhamento pedagógico dos estagiários, a resolução disciplinou duas modalidades de supervisão, conforme a seguir:

I - supervisão direta: acompanhamento e orientação do estagiário por meio de observação contínua e direta das atividades desenvolvidas no campo de estágio, por um profissional designado para ser supervisor de estágio;

II - supervisão semidireta: acompanhamento e orientação do estagiário por meio de orientações individuais e coletivas na UFPB ou no campo de estágio, bem como visitas sistemáticas ao campo de estágio pelo docente orientador, que manterá contatos com o profissional da unidade concedente responsável pelo estagiário (UFPB, 2015, p. 37, grifos nossos).

Particularmente, no estágio não obrigatório desenvolvido no âmbito da UFPB, o acompanhamento pedagógico dos estagiários-bolsistas é realizado diretamente pelo supervisor de estágio (servidor técnico-administrativo ou docente da UFPB) e pelo professor orientador de estágio (servidor docente da UFPB) e, indiretamente, pela gestão da CEM/PRG.

\section{Relação teoria-prática no estágio}

Pimenta e Lima (2012) sinalizam que a formação profissional não deve mais ocorrer nos moldes de um currículo normativo, em que primeiro se apresenta a ciência, depois a sua aplicação e, 
por último, um estágio que supõe a prática pelos alunos dos conhecimentos teóricos. As autoras alertam que o profissional assim formado não consegue dar respostas às situações que emergem no cotidiano profissional, porque estas ultrapassam os conhecimentos elaborados pela ciência e as respostas teóricas que esta poderia oferecer ainda não estão formuladas.

Dessa forma, Kulcsar (2012) assinala que o primeiro papel a ser questionado é o da universidade, pois ao fornecer uma bagagem teórica específica que exige uma visão crítica da sociedade vigente, ela parece não conseguir formar um profissional competente, capaz de reoperacionalizar a teoria em relação à prática. Nesse contexto, a autora defende que "um dos elementos de que a universidade dispõe e que poderia ser redimensionado é o estágio supervisionado, obrigatório em todos os currículos de Licenciatura e Pedagogia, mas não devidamente explorado" (KULCSAR, 2012, p. 57).

Pimenta (2012), ao pesquisar sobre o estágio na formação de professores, alerta que essa atividade tem sido explicitada com mais veemência por sua problemática da relação teoria e prática. Possivelmente porque o estágio tem sido compreendido como o "polo prático" dos cursos, oposto à "teoria" e, desta forma, aponta que "os educadores brasileiros, mais recentemente, têm colocado sua aposta (seu desejo) no estágio enquanto possibilidade privilegiada para o enfrentamento da unidade entre teoria e prática" (PIMENTA, 2012, p. 203).

Além disso, vale salientar também que, conforme Piconez (2012), o caráter complementar ou suplementar conferido à Prática de Ensino/Estágio Supervisionado, ou ainda, "uma teoria colocada no começo dos cursos e uma prática colocada no final deles sob a forma de Estágio Supervisionado, constituem a maior evidência da dicotomia existente entre teoria e prática" (p. 15). A autora ainda insere tal questão no contexto das críticas à inadequação ou pouca contribuição que os cursos de formação têm dado para o preparo efetivo de professores. Ressalta que a dissociação do ensino com a prática se tornou um problema governamental e um objeto de estudo de diferentes autores e projetos que propõem, sob várias formas, a unidade teoria e prática.

Convém, entretanto, salientar que "o estágio não é práxis. É atividade teórica, preparadora de uma práxis" (PIMENTA, 2012, p. 21 - grifos do autor), pois “práxis é a atitude (teórico-prática) humana de transformação da natureza e da sociedade. Ancorada na perspectiva marxiana de Vasquéz, a pesquisadora destaca: “Não basta conhecer e interpretar o mundo (teórico), é preciso transformálo (práxis)" (PIMENTA, 2012, p. 99). 
Nesse contexto, o estágio terá por finalidade proporcionar ao estudante uma aproximação à realidade na qual irá atuar. Portanto, não se deve conceber o estágio como o "polo prático" do curso, mas como uma experiência formativa que deve oportunizar se constituir numa reflexão sobre e a partir da realidade da instituição de ensino à luz dos conhecimentos teóricos necessários. É preciso que se assuma que a atividade ocorrerá, efetivamente, no momento em que o estudante for professor, na prática. Ou seja, um curso não é a prática docente, mas é a teoria sobre a prática docente e será tão mais formador à medida que as disciplinas todas tiverem como ponto de partida a realidade educacional brasileira (PIMENTA; GONÇALVES, 1990 apud PIMENTA, 2012, p. 20 - grifos do autor).

Com a prática da reflexão sobre a prática concebida e vivenciada teoricamente, são vislumbradas perspectivas de futuro proporcionadas por uma postura crítica, mais ampliada, que permitem perceber os problemas que permeiam as atividades e a fragilidade da prática (PICONEZ, 2012). Portanto, compete possibilitar no estágio dos cursos de formação de professores que os futuros docentes compreendam a complexidade das práticas institucionais e das ações aí praticadas por seus profissionais como alternativa na formação para sua inserção profissional (PIMENTA; LIMA, 2012).

Dessa forma, vale relembrar nossa compreensão de professor para além da docência, pois, segundo Libâneo, Oliveira e Toschi (2012, p. 419), para ser um participante ativo no processo de tomadas de decisões na instituição de ensino,

[...] o professor precisa conhecer bem a estrutura e a organização do ensino, as políticas educacionais e as normas legais, os mecanismos de sua elaboração e divulgação, bem como desenvolver habilidades de participação e de atuação em colaboração com os colegas de equipe. Essas são condições indispensáveis para que os sujeitos-professores não sejam tutelados pelas decisões externas. Ao contrário, se as aceitarem ou negarem, que o façam conscientemente, admitindo também a possibilidade de diálogo com as instâncias superiores.

Nesse sentido, conforme Fazenda (2012), o profissional que não consegue investigar questões específicas de sua área de conhecimento ou que não tenha tido oportunidade de pesquisarse a si mesmo, necessariamente, não terá condições de projetar seu próprio trabalho, de avaliar seu desempenho e de contribuir para a construção do conhecimento no âmbito das instituições de ensino. No âmbito do curso de Pedagogia, "a prática da reflexão sobre a prática tem favorecido as discussões sobre o processo pedagógico, suas multifaces e suas questões necessárias" (PICONEZ, 2012, p. 26).

$$
\text { Conforme Prado (2012, p. 19), }
$$


Não basta ao pedagogo conhecer teorias, perspectivas e resultados de investigação como fins em si mesmos - ele deve ser capaz de construir, a partir da relação intrínseca existente entre prática e teoria, soluções apropriadas para os diversos aspectos de sua ação profissional, o que requer não só a capacidade de mobilização e articulação de conhecimentos teóricos, mas também a capacidade de lidar com situações concretas, saberes que devem ser desenvolvidos progressivamente durante a etapa da formação inicial e ao longo da carreira profissional.

Portanto, no processo de formação do professor, o estágio supervisionado deve ser considerado um instrumento fundamental, já que poderá auxiliar o estudante a compreender e enfrentar o mundo do trabalho e contribuir para a formação de sua consciência política e social, unindo a teoria à prática. Mas, para que isso ocorra, o

[...] estágio não pode ser encarado como uma tarefa burocrática a ser cumprida formalmente [...]. Deve, sim, assumir a sua função prática, revisada numa dimensão mais dinâmica, profissional, produtora, de troca de serviços e de possibilidades de abertura para mudanças (KULCSAR, 2012, p. 58-59).

Dessa forma, o estágio se constitui como atividade relevante na formação de pedagogos, "tendo em vista as muitas aprendizagens que por meio dele se constroem, tanto no que se refere à percepção de como ocorre efetivamente a prática pedagógica, como no pensar esta por um viés teórico, articulando assim, teoria e prática" (LUZ; CAMARGO-SILVA, 2014, p. 152). Concordamos com Prado (2012) sobre ser indubitável a necessidade de que o futuro "pedagogo experiencie, como estudante, [...] as atitudes, os modelos didáticos, as capacidades e os modos de organização que poderão estar presentes em suas práticas administrativas e pedagógicas futuras" (PRADO, 2012, p. $50)$.

\section{Metodologia}

O trabalho empírico teve como foco os estagiários do curso de Pedagogia, Campus I (João Pessoa), contemplados com a bolsa-estágio e que realizavam atividades não diretamente relacionadas ao ensino na UFPB, bem como os seus respectivos supervisores e professores orientadores do estágio e a gestora da Coordenação de Estágio e Monitoria (CEM) vinculada à Pró-Reitoria de Graduação (PRG), pois considerávamos que estes eram atores estratégicos no processo do estágio em estudo. Na seleção dos estagiários, realizada no 20 semestre de 2016, preocupamo-nos em incluir estudantes que estivessem cursando ou já tivessem cursado a disciplina obrigatória de "Estágio Supervisionado I", pois 
entendemos que a experiência deste componente curricular se relaciona diretamente com nosso objeto de pesquisa, resultando em alunos matriculados a partir do 4o período letivo do curso. Já os supervisores e os professores orientadores foram selecionados a partir desses estagiários, em que contemplamos, no mínimo, um deles em cada local de estágio (unidade concedente).

Ao todo, foram entrevistados 17 (dezessete) sujeitos, sendo uma gestora (Servidora/Docente da área da Educação), duas supervisoras (Servidoras/Pedagogas), quatro orientadores (Servidores/Docentes da área da Educação) e 10 (dez) estagiários, vinculados a cinco unidades concedentes, conforme detalhamento no quadro a seguir:

Quadro 1 - Sujeitos entrevistados na pesquisa

\begin{tabular}{|c|c|c|c|c|}
\hline Gestor & $\begin{array}{l}\text { Supervisor e } \\
\text { Orientador }\end{array}$ & Estagiário & Local de estágio (Setor/projeto9) & $\begin{array}{c}\text { Unidade } \\
\text { concedente }\end{array}$ \\
\hline \multirow{10}{*}{$\begin{array}{l}\text { Gestora da } \\
\text { CEM/PRG }\end{array}$} & \multirow[b]{2}{*}{ Orientador CE } & Estagiário 1-CE & Setor da Direção de Centro & \multirow[b]{2}{*}{$\begin{array}{l}\text { Centro de } \\
\text { Educação } \\
\quad \text { (CE) }\end{array}$} \\
\hline & & Estagiária 2-CE & $\begin{array}{l}\text { Setor do Núcleo Interdisciplinar de } \\
\text { Pesquisa e Ação sobre Mulher e } \\
\text { Relações de Sexo e Gênero }\end{array}$ & \\
\hline & \multirow{3}{*}{$\begin{array}{c}\text { Supervisora } \\
\text { PRG } \\
\text { Orientadora } \\
\text { PRG }\end{array}$} & Estagiária 3-PRG & $\begin{array}{c}\text { Setor da Coordenação de Estágio e } \\
\text { Monitoria }\end{array}$ & \multirow{3}{*}{$\begin{array}{l}\text { Pró-Reitoria de } \\
\text { Graduação (PRG) }\end{array}$} \\
\hline & & Estagiária 4-PRG & $\begin{array}{c}\text { Setor da Coordenação de Currículos e } \\
\text { Programas }\end{array}$ & \\
\hline & & Estagiária 5-PRG & $\begin{array}{c}\text { Setor da Coordenação de } \\
\text { Escolaridade }\end{array}$ & \\
\hline & Supervisora CCS & Estagiária 6-CCS & $\begin{array}{l}\text { Setor da Direção de Ensino } \\
\text { da Escola Técnica de Saúde }\end{array}$ & $\begin{array}{c}\text { Centro de } \\
\text { Ciências da Saúde } \\
\text { (CCS) } \\
\end{array}$ \\
\hline & \multirow{2}{*}{$\begin{array}{l}\text { Orientadora } \\
\text { CPA }\end{array}$} & Estagiária 7-CPA & $\begin{array}{l}\text { Projeto de Avaliação das Políticas } \\
\text { Acadêmicas }\end{array}$ & \multirow{2}{*}{$\begin{array}{l}\text { Comissão Própria } \\
\text { de Avaliação } \\
\text { (CPA) }\end{array}$} \\
\hline & & Estagiária 8-CPA & $\begin{array}{l}\text { Projeto de Avaliação da } \\
\text { Infraestrutura Física }\end{array}$ & \\
\hline & \multirow{2}{*}{ Orientadora $\mathrm{CIA}$} & Estagiária 9-CIA & $\begin{array}{l}\text { Projeto Grupo de Trabalho } \\
\text { Empoderar para Crescer }\end{array}$ & \multirow{2}{*}{$\begin{array}{l}\text { Comitê de } \\
\text { Inclusão e } \\
\text { Acessibilidade } \\
\text { (CIA) }\end{array}$} \\
\hline & & Estagiária 10-CIA & $\begin{array}{l}\text { Projeto Grupo de Trabalho } \\
\text { Acessibilidade Pedagógica }\end{array}$ & \\
\hline
\end{tabular}

Fonte: Dados da pesquisa, 2016.

\footnotetext{
${ }^{9}$ Embora as cinco unidades concedentes pertençam a mesma Universidade, passaremos a nos referir por "Setor", os locais onde os estágios foram realizados, já que ocorreram em órgãos administrativos do CE, da PRG e do CCS; ao passo que nomeamos por "Projeto" os estágios realizados na CPA e na CIA, pois estes desenvolvem as atividades de estágio através de projetos de pesquisa.
} 
Com todos os sujeitos, foi realizada uma entrevista semiestruturada ${ }^{10}$, por meio de três roteiros diferentes: um para a gestora da Coordenação de Estágio; um para os supervisores/orientadores e um para os estagiários. Cada entrevista ocorreu no próprio ambiente de atividade do sujeito e durou em média 20 (vinte) minutos, sendo o áudio gravado e transcrito para a posterior análise.

Em seguida, procedemos com a análise de conteúdo ${ }^{11}$ das entrevistas, sob a perspectiva de Bardin (1979), que consistiu em três etapas: pré-análise (leitura compreensiva das entrevistas, elaboração dos primeiros pressupostos para a interpretação e escolha das formas de classificação da análise), exploração do material e tratamento dos resultados (distribuição de trechos do material nos esquemas de classificação, leitura de diálogo entre as partes dos textos selecionados, inferência e análise dos núcleos de sentido, reagrupamento das partes dos textos por temas e elaboração da redação temática que articulou os temas com as categorias que guiaram a interpretação) e síntese interpretativa (texto final que fez dialogar os temas com os objetivos, questões e hipóteses da pesquisa)

\section{Resultados e discussão}

A partir do relato dos entrevistados - Gestora, Supervisoras/Orientadores e Estagiários passaremos, a seguir, a apresentar e discutir os resultados da pesquisa. Primeiramente, sobre o acompanhamento do estágio e, em seguida, sobre a relação teoria-prática no estágio.

\section{O que dizem os entrevistados sobre o acompanhamento do estágio?}

Quanto ao acompanhamento pedagógico do estágio, ao questionarmos a gestora da CEM/PRG, houve referência apenas ao supervisor do estágio e menção do gestor do setor/projeto,

\footnotetext{
${ }^{10}$ Trata-se da utilização de um roteiro previamente elaborado com questionamentos básicos que são apoiados em teorias e hipóteses que se relacionam ao tema da pesquisa que favorece não só a descrição dos fenômenos sociais, mas também sua explicação e a compreensão de sua totalidade (TRIVIÑOS, 1987, p. 152).

11 É um conjunto de técnicas das comunicações visando obter, através de procedimentos sistemáticos e objetos de descrição do conteúdo das mensagens, indicadores (quantitativos ou não) que permitam inferir conhecimentos relativos às condições de produção/recepção (variáveis inferidas) dessas mensagens (BARDIN, 1979, p. 42).
} 
sem haver referência ao professor orientador. Além disso, foi relatado que a atribuição da Coordenação de Estágio nesse processo se concentrou apenas mediante a análise documental, para fins de regularização, conforme a seguir:

\begin{abstract}
Em toda documentação vem a indicação do supervisor de estágio. E esse estagiário fica sob sua supervisão. Toda a vida dele ali enquanto estagiáriobolsista é regida por esse supervisor, com o aval do administrador geral do setor. [...] Então, não há como não haver essa orientação. Essa orientação precisa ser dada em todos os sentidos, como se portar, como receber as pessoas, como tratar. Se for um caso de uma atuação mais em termos administrativos, como atender o telefone, como dar uma orientação pra alguém que chega. Então tudo isso o supervisor fica observando e vai orientando o seu estagiário, pelo menos é isso que a gente espera. Que esse aluno realmente passe por uma transformação, que ele altere alguma coisa no seu processo de formação, que ele saia de um lugar para outro, como se diz em Educação. Ou seja, que esse período de estágio dele realmente seja produtivo para o estagiário. E o supervisor é a pessoa que tem um papel fundamental nesse processo. Em termos de instrumentos cada setor tem uma forma [...] O documento que ele tem de apresentar à CEM da bolsaestágio é o relatório [...] assinado pelo supervisor de estágio, pelo professor orientador e por ele mesmo (Gestora da CEM/PRG).
\end{abstract}

Já na visão dos supervisores/orientadores de estágio, quando questionados acerca das metodologias adotadas para o acompanhamento do estagiário, percebemos que a avaliação é realizada de forma processual, por meio da adoção de estratégias subjetivas, como observações/reuniões e de instrumentos objetivos, como frequência e relatório:

Sempre tentando ver as limitações pra tentar contribuir e tentar superar juntos. Além da minha supervisão, como a orientadora é a gestora do setor, nesse caso específico estava tudo interligado (Supervisora PRG).

No dia a dia, observando. Hoje mesmo ela preencheu o relatório pra ser anexado à renovação. Mas eu acompanho mais no dia a dia, pois a gente trabalha na mesma sala, no mesmo ambiente. Nosso contato é direto. $\mathbf{0}$ professor orientador eu até sei quem é, porque ela me disse, mas não existe nenhum contato (Supervisora CCS, grifo nosso).

Esses estagiários estão ligados diretamente ao projeto, e o responsável pelo projeto é o orientador. Então a avaliação é passada para mim, enquanto supervisora [...] E esse é um processo contínuo. O estágio precisa ser acompanhado cotidianamente [...] e precisa dessa participação dele efetiva, esse é o grande objetivo do estágio, essa experiência, essa troca (Orientadora CPA).

O acompanhamento acredito que ele seja semanal, pelo menos da minha parte toda semana eu sei o que está acontecendo com cada um. E eles vêm trazer as demandas conforme elas vão surgindo, fora as reuniões que têm pra 
eles poderem resolver. Essa avaliação é processual [...] A gente tem uma folha de frequência [...] E tem um relatório final de atividades [...] Então, é um acompanhamento processual, não tem muito como o estagiário sumir ou se perder, porque como tem muito serviço e muita demanda, se ele não vier fica complicado (Orientadora $\mathrm{CIA}$ ).

Ainda, na compreensão deles, suas atribuições adotadas diante do estagiário vão desde a supervisão/orientação individual até a realização de reuniões do setor/projeto coletivas, conforme verificado nos trechos a seguir.

A gente diz como é o setor, como é o funcionamento, a finalidade do trabalho que a gente faz aqui [...] E as responsabilidades a gente diz também, coloca pra eles a parte administrativa [...] E outras atividades que eles possam fazer aqui, como atendimento, tanto de professor como de aluno (Orientadora PRG).

Temos a responsabilidade do acompanhamento, a questão da frequência do estagiário também é importante. A realização, por eles, dos relatórios. E nós aqui cobramos os relatórios parciais e finais. Não só o que vai pra PRG, aquele relatório mais condensado, mas um relatório das atividades. E aí, com isso, nós vamos tendo um apanhado mais fidedigno de como está ocorrendo o trabalho (Orientadora CPA).

Eu me coloco como um suporte, como uma pessoa disponível, não sou orientadora só deles, mas de todos os que eu sou, me coloco uma pessoa pra dar o suporte, o acolhimento que precisar, em termos de legislação e, principalmente, de formação. [...] Eu acho que o nosso papel de orientador e de supervisor é dar um apoio constante, permanente e integral. Indicação de leituras, acontece bastante, principalmente via e-mail, mando um texto e cobro na próxima supervisão que tiver na próxima orientação (Orientadora $\mathrm{CIA}$.

Podemos considerar que as estratégias adotadas e as atribuições assumidas pelos supervisores/orientadores possibilitam um acompanhamento que favorece uma formação mediada principalmente pela rotina prática do estágio, mas também, em alguns momentos, por sua reflexão teórica. Ainda quanto à visão dos supervisores/orientadores e dos estagiários em relação ao acompanhamento, não houve referência ao papel da CEM/PRG, e podemos sintetizar este acompanhamento em duas situações: supervisor e orientador realizando acompanhamento diário, quando ambos estão lotados no mesmo setor/projeto; e supervisor ou orientador realizando acompanhamento diário, quando apenas um está lotado no mesmo setor/projeto. 
Isso ocorre porque no âmbito específico da bolsa-estágio, modalidade de estágio curricular supervisionado não obrigatório interno, a instituição de ensino, a parte concedente e o educando fazem parte da mesma Instituição, a UFPB. Portanto, sendo o supervisor e o orientador de estágio servidores públicos da mesma Universidade, e o estagiário também vinculado a esta, a tríade supervisor-orientador-estagiário poderia estar bem articulada. Entretanto, não é o que o relato de alguns estagiários indica: [...] meu contato maior foi com o [...] supervisor. [...] praticamente todos os dias [...] a gente tem uma boa relação a respeito do trabalho. Já o professor orientador não. Seria interessante sentar, até porque pela construção do conhecimento, porque enquanto eu estou falando com eles eu também estou aprendendo, e justamente construindo um conhecimento para levar para o resto da vida (Estagiário 1-CE).

O orientador do meu curso, ele só tem mesmo o passo de ter me informado a matrícula SIAPE. Desde o início foi dito isso na ETS, o orientador somente vai precisar assinar os relatórios e mais nada. Quanto à supervisora, é ótima, pra mim ela passa tudo. [...] tudo que eu tiver dúvida ela me ajuda (Estagiária 10-CCS)

A orientadora e a supervisora sempre nos ajudam muito, elas acompanham bem, apesar da gente não tá lá fisicamente sempre, porque a gente tem que está transitando. Mas qualquer dúvida que a gente tem, seja pessoalmente ou via rede social, elas acompanham bem, sem problemas (Estagiária 7-CPA).

Conforme salientado no relato dos estagiários, o acompanhamento apesar de satisfatório, ainda precisa ser aprimorado. Também percebemos que há uma fragilidade na interação entre os agentes responsáveis pelo acompanhamento do estágio: em nível estratégico (CEM/PRG), tático (supervisor/orientador) e operacional (estagiário).

O papel do orientador surge, por vezes, apenas como exigência da legislação, figurando na formalização dos documentos do estágio, conforme se percebe em alguns casos. Embora os estagiários relatem uma boa relação interpessoal nesse acompanhamento, eles desconhecem as reais atribuições do supervisor e/ou do orientador de estágio. Além disso, há supervisores que não mantêm contato com o orientador e vice-versa.

Zaidan (2011, p. 25), ao pesquisar a necessária articulação entre orientação e supervisão no estágio curricular, conclui que "quanto maior a articulação durante todo o processo, mais qualidade de recepção, informação e orientação terá o estagiário no período de sua formação prática". Nessa perspectiva, após identificarmos essa lacuna, podemos sugerir/aperfeiçoar mecanismos de maior aproximação/integração entre esses atores, bem como o redimensionamento para melhor clareza dos papéis de cada elemento envolvido no estágio. 


\section{O que dizem os entrevistados sobre a relação teoria-prática no estágio?}

Quanto à visão dos entrevistados sobre a relação teoria-prática, passaremos a analisar, primeiramente, o relato da Coordenadora de Estágio para, em seguida, analisarmos a percepção dos supervisores/orientadores e estagiários. No que concerne à visão da gestão da CEM/PRG, a coordenadora reconhece que o estagiário só terá uma melhoria na sua formação "[...] se essas atividades do estágio estiverem [...] direcionadas para o curso dele, para a melhoria da formação dele, para a ampliação da formação dele" (Gestora da CEM/PRG). E, nesse sentido, ressalta que "essa formação é feita in loco, os próprios gestores que recebem os estagiários-bolsistas vão orientando e essa formação é feita" (Gestora da CEM/PRG). Entretanto, cabe questionar em que medida tais orientações são fundamentadas explicitamente numa teoria ou se elas remetem a prescrições de natureza prática, sem respaldo teórico consistente, restando ao estagiário apenas segui-las.

Quanto à visão das supervisoras, ao serem indagadas sobre como acontece a relação teoriaprática no estágio, duas servidoras fizeram referência ao reconhecimento da fragilidade e do distanciamento entre o binômio curso-estágio e, portanto, identificamos a necessidade de haver o fortalecimento da relação teoria-prática:

[...] falta mais proximidade [...] esse vínculo, pode ser fortalecido. E [...] como eu sou formada em Pedagogia, posso dizer que o curso ele é muito teórico e realmente falta mais prática. [...] Então, do curso o que falta é uma maior aproximação entre a teoria que ele está estudando na parte de gestão dos processos, de planejamento, de organização setorial e o que desenvolvemos aqui na PRG. Entretanto, existem relações tanto indiretas, [...] que são as relações próprias do [...] universo do trabalho administrativo, quanto questões que são próprias do curso de Pedagogia da parte de gestão, que é [...] colaborar com o gestor de um programa acadêmico. Então ele está organizando eventos, colaborando para pensar os instrumentos de avaliação. Então tudo isso está diretamente ligado à área de formação, que da Pedagogia é o planejamento, a avaliação, tudo isso está ligado (Supervisora PRG).

[...] eu acredito que o trabalho que ela faz aqui não tem uma relação direta com o que ela estuda lá, no momento não, eu não sei em outras disciplinas. [...] Então ela está muito voltada pra esse conhecimento que a gente não utiliza aqui, em outro momento até pode ser, mas no momento eu tenho percebido que não. [...] (Supervisora CCS).

Apesar disso, os supervisores/orientadores relataram o desenvolvimento de ações para melhor articular a vivência prática do estágio com o que é discutido no curso. Isso ocorre no caso da 
reserva de um horário específico para reflexões no projeto, como na fala da Orientadora CIA relatando que "nas reuniões é que discutimos um conteúdo mais teórico", ou mesmo durante a conveniência possibilitada pelo próprio setor, conforme a seguir.

[...] quando tem uma oportunidade eu estou sempre orientando leituras, discutindo alguma questão com eles. Pergunto o que eles estão estudando lá no curso que eles possam trazer pra cá. Procuro fazer essa compatibilização entre o que eles estão estudando no curso de Pedagogia e o que estão vendo aqui (Orientadora PRG).

Quando os estagiários foram estimulados a relatar a relação teoria-prática advinda do estágio, sobretudo quanto aos conhecimentos e saberes desenvolvidos no curso de Pedagogia e as atividades do estágio, e vice-versa, eles destacaram, em sua maioria, a existência desta relação, assim como os supervisores/orientadores. Entretanto, os estudantes também reconheceram a carência de uma maior articulação entre o curso e o estágio, conforme depoimentos a seguir:

Sim, com certeza existe relação, até porque no curso de Pedagogia a gente tem uma disciplina e um estágio em gestão educacional. E aqui não deixa de ser uma gestão educacional, só que em nível superior. O curso dá subsídio sim, mas não para tratar como uma forma burocrática, mas pra você entender realmente como que é uma gestão que é posta na teoria e como ela acontece na prática. Há sim uma articulação, e você consegue perceber na vivência a teoria também. O estágio também contribui para o curso, é bem significante [...] (Estagiário 1-CE).

Então, tudo o que eu tenho aprendido sobre gestão tem sido no estágio, não é no curso. [...] Claro que a experiência, dos textos, das coisas que vêm me passando, eu vou associando. Mas eu percebo que eu tenho aprendido mais no estágio, a respeito do setor [...] Quando eu realizei a disciplina de gestão, foi quando eu vim ver alguma coisa do que eu faço lá na ETS [...] que foi quando a gente também foi pra campo [...] pra direção da escola [...] (Estagiário 6-CCS).

[...] do curso para o estágio é pouco [...] A gente paga a cadeira de gestão, é pouca coisa que a gente vê na teoria e a prática é imensa. Então na verdade a gente traz um pouco daquela teoria, mas a gente aprende mesmo é na prática. A prática, o projeto que eu estou é quem ensina mais. A teoria que a gente vê dentro da sala de aula é só uma base pra nos ajudar, mas na verdade se você não correr atrás desses projetos você não aprende muita coisa não (Estagiária 8-CPA).

Como lá no CIA e a minha área de aprofundamento é em educação especial, tem tudo a ver, fala sobre inclusão, acessibilidade, deficiências. E lá tá sempre em contato com esse público, então existe relação (Estagiária 10-CIA).

Percebemos que os estagiários mobilizam seus conhecimentos pedagógicos a partir da 
referência, por exemplo, de componentes curriculares como a disciplina de "Gestão Educacional" e o “Estágio Supervisionado I - Gestão Educacional” (Estagiário 1-CE e Estagiária 8-CPA), e da área de aprofundamento em Educação Especial (Estagiária 10-CIA). Entretanto, em alguns casos essa relação não vem ocorrendo de maneira intencional e sistemática, mas sim por um esforço do estudante em relacionar seus saberes. As passagens da fala da Estagiária 8-CPA, como "é pouca coisa que a gente ver na teoria e a prática é imensa", "a gente aprende mesmo é na prática” e "a prática, o projeto que eu estou é quem ensina mais", representam a dicotomia ainda existente entre a teoria e a prática, bem como a tendência de supervalorizar a prática em detrimento da teoria, que também é reforçada na fala a seguir:

[...] no curso em si eu não posso dizer que tive contribuições enormes em relação à gestão. Eu vim realmente aprender quando eu comecei a bolsaestágio aqui na PRG, porque eu vi realmente como ocorria em relação a tudo. [...] Então por isso eu digo que a parte de gestão, realmente, eu só vim aprender aqui. O curso em si não me ensinou, eu vim aprender aqui (Estagiária 4-PRG).

Entretanto, Piconez (2012) salienta que esse contexto relacional deve ser orientado para o conceito da unidade, ou seja, da teoria e prática articuladas e não apenas dissociadas ou justapostas. O estágio deve ser concebido segundo a perspectiva dialética, sendo seu processo planejado a partir dos fundamentos didático-pedagógicos do curso.

Além de reconhecerem essa relação teoria-prática fragilizada, uma das supervisoras e uma das estagiárias percebem que o curso de Pedagogia forma, prioritariamente, para a dimensão da docência, mais especificamente para a sala de aula, conforme se verifica nos relatos a seguir:

A questão da formação na gestão, isso também faltou na minha formação, que foi pedagógica voltada pra sala de aula. Eu não tive nenhuma disciplina voltada pra gestão educacional. Se eu tivesse feito, certamente, contribuiria muito em meu trabalho. Portanto, eu não sei te dizer que conteúdo, o que eles deveriam melhorar ou buscar, mas com certeza esse estágio influencia positivamente (Supervisora CCS).

[...] lá no curso a gente é trabalhado para sala de aula [...] não nos ensinam, não nos passam a teoria, se for pra ficar como eu estou agora numa direção. [...] porque o que eu aprendo lá no curso é sobre a sala de aula, tanto no fundamental, infantil, médio. Lá eles nos ensinam, nos indagam, para aprender sala de aula, não muito o setor de gestão (Estagiário 6-CCS).

Esses relatos vão ao encontro do que salienta Munhós (2007), pois nos cursos de Pedagogia são percebidas preocupações em definir um aprofundamento profissional prioritário na área da 
docência, secundarizando a formação do gestor e do pesquisador, que são também funções indispensáveis à formação do Pedagogo. Assim, a docência como o eixo articulador do curso prevalece como perspectiva de formação, minimizando a oportunidade de estudos relacionados a outras dimensões não diretamente relacionadas ao processo de ensino-aprendizagem no âmbito da sala de aula.

\section{Considerações Finais}

Apesar de os apontamentos legais e teóricos indicarem o eixo teoria-prática como norte para o desenvolvimento da experiência do estágio, constatamos a fragilidade da relação curso-estágio e, portanto, também da articulação teoria-prática. Isso, possivelmente, pode ser minimizado a partir da articulação entre a gestão administrativa da CEM/PRG, o acompanhamento pedagógico do supervisor e orientador de estágio e o perfil de formação do curso de Pedagogia da UFPB/Campus I - que prioriza a docência, conforme relataram os entrevistados. Nesse sentido, faz-se necessário destacar que a possível fragilidade na formação do gestor e do pesquisador é um aspecto crucial a ser discutido na pauta das diretrizes curriculares para formação do Pedagogo.

Além disso, percebemos que é imperativo favorecer instrumentos/práticas de gestão que aproximem a Coordenação de Estágio da Universidade ao acompanhamento pedagógico desenvolvido pelo supervisor e pelo orientador de estágio, articulando as atividades do estagiário ao contexto curricular do curso de Pedagogia. Essa aproximação poderá contribuir para o fortalecimento da relação teoria-prática segundo uma perspectiva unitária, que pressupõe a teoria e a prática como núcleo articulador, sendo, assim, indissociáveis (PIMENTA, 2012), priorizando a formação do estagiário que, antes disto, é estudante.

A partir desse contexto relacional, consideramos imprescindível planejar, acompanhar e avaliar as atividades do estágio a partir dos fundamentos didático-pedagógicos do currículo do curso de Pedagogia UFPB/Campus I. Nesse sentido, a experiência do estágio poderá ser permeada por uma reflexão teórica consistente e, para isto, é fundamental o papel da supervisão e da orientação do estagiário-bolsista. Portanto, o estágio do estudante de Pedagogia, mesmo quando desenvolvido na modalidade não obrigatória e em área não prioritária do curso - Gestão e Pesquisa no âmbito da Educação Superior, poderá articular suas diferentes dimensões e proporcionar ao graduando experiências complementares nas distintas áreas de atuação do Pedagogo: a docência, a gestão e a pesquisa. 


\section{Referências}

BARDIN, L. Análise de conteúdo. Lisboa: Edições 70, 1979.

BRASIL. Lei № 9.394, de 20 de dezembro de 1996. Estabelece as diretrizes e bases da educação nacional. Brasília, DF, 1996.

. Resolução CNE/CP № 1, de 15 de Maio de 2006. Diretrizes Curriculares Nacionais para o Curso de Graduação em Pedagogia, licenciatura. Brasília, DF, 2006.

. Lei № 11.788, de 25 de setembro de 2008. Dispõe sobre o estágio de estudantes e dá outras providências. Brasília, DF, 2008.

. Resolução CNE/CP № 2, de 01 de Julho de 2015. Define as Diretrizes Curriculares Nacionais para a formação inicial em nível superior (cursos de licenciatura, cursos de formação pedagógica para graduados e cursos de segunda licenciatura) e para a formação continuada. Brasília, DF, 2015.

. Orientação Normativa MPOG № 2, de 24 de Junho de 2016. Estabelece orientações sobre a aceitação de estagiários no âmbito da Administração Pública federal direta, autárquica e fundacional. Brasília, DF, 2016.

. Resolução CNE/CP № 1, de 9 de Agosto de 2017. Altera o Art. 22 da Resolução CNE/CP № 2, de 1ำ de 2015. Brasília, DF, 2017.

FAZENDA, I. C. A. O papel do estágio nos cursos de formação de professores. In: PICONEZ, S. C. B. et al. (Coords.), A prática de ensino e o estágio supervisionado. 24. ed. Campinas, SP: Papirus, 2012. p. 4755.

KULCSAR, R. O estágio supervisionado como atividade integradora. In: PICONEZ, S. C. B. et al. (Coords), A prática de ensino e o estágio supervisionado. 24. ed. Campinas, SP: Papirus, 2012. p. 57-67.

LIBÂNEO, J. C.; OLIVEIRA, J. F.; TOSCHI, M. S. Educação escolar: políticas, estrutura e organização. São Paulo: Cortez, 2012.

LUZ, T. F. C.; CAMARGO-SILVA, S. S. Estágio em gestão escolar: pensando e produzindo um outro olhar. In: UJIIE, N. T.; ANSAI, R. B. Estágio supervisionado no curso de pedagogia: ação integrativa e definição de contornos teórico-práticos. Curitiba: CRV, 2014. p. 83-95.

MUNHÓS, M. M. LDB \& DIRETRIZES CURRICULARES NACIONAIS: A FORMAÇÃO EM CURSOS DE PEDAGOGIA. 2007. 140 f. Dissertação (Mestrado) - Universidade do Estado de Minas Gerais, Fundação Educacional de Divinópolis, Divinópolis, 2007.

PICONEZ, S. C. B. et al. (Coord.). A prática de ensino e o estágio supervisionado. 24. ed. Campinas, SP: Papirus, 2012.

PIMENTA, S. G. 0 estágio na formação de professores: unidade, teoria e prática? 11. ed. São Paulo: Cortez, 2012.

PIMENTA, S. G.; LIMA, M. S. L. Estágio e docência. 7. ed. São Paulo: Cortez, 2012.

PRADO, E. Estágio na licenciatura em pedagogia: gestão educacional. Petrópolis, RJ: Vozes; Maceió, AL: Edufal, 2012.

TRIVINOS, A. N. S. Introdução à pesquisa em ciências sociais: a pesquisa qualitativa em educação. São Paulo: Atlas, 1987. 
UNIVERSIDADE FEDERAL DA PARAÍBA (UFPB). Resolução CONSEPE № 64/2006. Projeto PolíticoPedagógico do Curso de Graduação em Pedagogia, Licenciatura, do Centro de Educação, Campus I, da Universidade Federal da Paraíba. João Pessoa, PB, 2006.

. Resolução CONSEPE № 16/2015. Aprova o regulamento dos cursos regulares de graduação da Universidade Federal da Paraíba. João Pessoa, PB, 2015.

. Instrução Normativa Conjunta PROGEP/PROPLAN/PRG/GR № 01/2016. Dispõe sobre os procedimentos relativos à solicitação da contratação de estagiários, modalidade de estágio curricular supervisionado não-obrigatório interno (bolsa-estágio), para o âmbito dos setores administrativos e acadêmicos da UFPB. João Pessoa, PB, 2016.

ZAIDAN, S. A necessária articulação entre orientação e supervisão no estágio curricular. Paideia. Belo Horizonte, Ano 8, n. 10, p. 11-28, 2011.

Recebido em: 28/09/2017

Aceito em: 29/12/2017 